\title{
Importância das características morfológicas e agronômicas no estudo da biodiversidade genética em milho
}

\section{Importance of morphological and agronomic characteristics in the study of genetic biodiversity in maize}

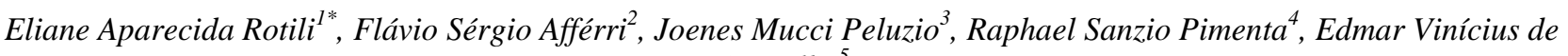 \\ Carvalho ${ }^{5}$
}

\begin{abstract}
Resumo: O milho, um dos cereais mais utilizados no mundo para alimentação humana e animal, é fonte de renda para várias famílias, quer seja na agricultura familiar ou em grandes propriedades. O trabalho teve como objetivo reunir resultados de pesquisas publicadas em periódicos revelando a importância relativa de características morfológicas e agronômicas da diversidade genética em milho. Devido à importância econômica e social deste cereal, a identificação de genótipos produtivos, sob condições ótimas ou de estresses, oriundos de diferentes programas de melhoramento genético, pode trazer grandes benefícios, tais como o aumento da produção e redução de insumos que reflete, em última instância, em uma diminuição de custos de produção e impactos ambientais. Neste sentido, é necessário conhecer a importância relativa de características para estudos sobre a diversidade genética, que podem auxiliar na escolha de genótipos potencialmente promissosres para as diferentes condições de cultivo. Na estimativa da importância relativa, os atributos encontrados com maior frequência nos trabalhos estudados foram: produtividade de grãos, altura de espiga, altura de planta, comprimento de espiga, diâmetro de espiga e massa de grãos.
\end{abstract}

Palavras-chaves: Zea mays L.; melhoramento genético; análise multivaridada; importância relativa.

Abstract: Maize is one of the most commonly used cereal in the world, as in food or feed, and it is source of income for many families). The aim of this work was reunite the results of scientific articles about the relative importance of morphological and agronomic traits on maize genetic diversity. Due to the economic and social importance of this cereal, the identification of productive genotypes under stress conditions or not, from various breeding programs, can be promote benefits such as increased production, reduction of inputs and thus with decrease of production costs and environmental impacts. In this case, it is essential to know the relative importance of the traits for the study of genetic diversity, and this results can help in choosing genotypes for use in breeding programs in different conditions. In the estimate of relative importance, the traits with more frequency in the articles were: grain yield, ear and plant height, ear length and diameter and grain weight.

Key words: Zea mays L.; breeding; multivariate analysis; relative importance.

\footnotetext{
*Autor para correspondência

Recebido para publicação em 21/09/2015; aprovado em 20/12/2105

${ }^{1}$ Dr. Biodiversidade e Biotecnologia, Rede de Biodiversidade e Biotecnologia da Amazônia Legal - BIONORTE, Gurupi, TO, (63) 8115 5420, elianerotili@yahoo.com..br

${ }^{2}$ Dr. Professor Universidade Federal de São Carlos -UFSCAR, flavio@uft.edu.br

${ }^{3}$ Dr. Professor Universidade Federal do Tocantins - UFT, joenesp@uft.edu.br

${ }^{4}$ Dr. Professor Universidade Federal do Tocantins - UFT, bioraph@yahoo.com.br

${ }^{5}$ Dr. Produção Vegetal, Universidade Federal do Tocantins - UFT, carvalho.ev.@uft.edu.br
} 


\section{INTRODUÇÃO}

O milho (Zea mays L.) é consumido e cultivado e em todos os continentes, devido principalmente a sua importância na alimentação animal, humana e na utilização da matériaprima para a indústria (BARAVIERA et al.,2014).

A divergência genética é de grande importância para o conhecimento da variabilidade genética das populações por possibilitar o monitoramento dos bancos de germoplasma e gerar informações úteis para preservação e o uso dos recursos genéticos vegetais (CRUZ et al., 2011).

No melhoramento de plantas, a divergência genética desempenha papel importante, pois, quando adequadamente explorada, pode reduzir a vulnerabilidade da cultura a doenças, acelerar o progresso genético para determinados caracteres e ser útil na síntese de novas populações (CUI et al., 2001).

O conhecimento do grau de divergência genética e da capacidade de combinação entre genótipos ou populações, segundo Kurek et al. (2001) é importante para a orientação de ações do melhoramento genético. A presença de variabilidade genética entre os acessos de germoplasmas é essencial na formação da população base. Entretanto, resultados satisfatórios somente são obtidos se o germoplasma utilizado como genitor possuir também alta média para as características de interesse (MELO et al., 2001).

Em programas de melhoramento de milho, visando à obtenção de linhagens superiores, a escolha de populações base com alto potencial de rendimento de grãos é fundamental. Neste sentido, estudos sobre a divergência genética poderiam auxiliar na identificação de tais populações (OLIBONI et al., 2012).

Assim, o presente trabalho teve como objetivo reunir resultados de pesquisas publicadas em periódicos revelando a importância relativa de características morfológicas e agronômicas da diversidade genética em milho.

\section{METODOLOGIA}

Foram realizados levantamentos sobre a temática abordada por meio de consultas a acervos bibliográficos publicados em periódicos de relevância, dissertações, teses, livros e consultas a dados disponíveis em endereços eletrônicos de base técnica e científica.

Para isso, a busca bibliográfica foi realizada via web nas bases de dados do portal da CAPES, Scielo nos idiomas inglês e português.

\section{REVISÃO BIBLIOGRÁFICA}

\section{A divergência genética}

A avaliação da divergência genética se destina à identificação de genitores contrastantes para serem utilizados em programas de melhoramento genético de espécies vegetais, uma vez que quanto mais divergentes forem os genitores, maior a variabilidade resultante na população segregante e maior a probabilidade de reagrupar os alelos em novas combinações favoráveis (BARBIERI et al., 2005). Além disso, possibilita a identificação de duplicatas, reduzindo assim, gastos consideráveis na manutenção de bancos de germoplasma (RODRIGUES et al., 2002).
No entanto, quando se dispõe de um número elevado de genótipos para avaliação há dificuldades operacionais nas práticas de hibridação artificial, dificultando a obtenção dessas combinações. Dessa forma, as técnicas multivariadas são ferramentas que podem ser utilizadas para minimizar essas dificuldades. Além disso, permitem combinar as múltiplas informações contidas na unidade experimental, caracterizando os genótipos com base em um conjunto de variáveis, principalmente se o objetivo é o melhoramento de caracteres quantitativos, como a produção (MISSIO et al., 2007).

A grande importância dos estudos de divergência genética está no conhecimento do grau de variabilidade genética das populações, em função da preocupação que ocorre com a erosão genética que diminui a variabilidade das populações decorrente, principalmente, das pressões de seleção aplicadas nos programas de melhoramento que visam resultados a curtos prazos, além da substituição de variedades mais antigas por populações geneticamente mais uniformes (AMARAL JÚNIOR; THIÉBAUT, 1999).

Por meio da diversidade genética, podem-se indicar progenitores geneticamente distantes para cruzamentos onde se procure obter o efeito heterótico na geração híbrida e maior probabilidade de recuperação de segregantes superiores em gerações avançadas (AMARAL JÚNIOR; THIÉBAUT, 1999; CRUZ et al., 2004).

Nos programas de melhoramento são utilizados inúmeros genitores que geram centenas de novas linhagens a cada ano. Desta forma, surge a dificuldade quanto aos estudos de capacidade de combinação para determinação dos grupos heteróticos, que estão altamente correlacionados com a divergência genética entre os genitores (SIMON et al., 2012). Assim, o estudo de características morfológicas e agronômicas das plantas cultivadas é importante para se conhecer a divergência genética do conjunto de germoplasma disponível para fins de utilização em programa de melhoramento genético (GONÇALVES et al., 2014).

Segundo Hallauer e Miranda-Filho (1995) maior atenção deve ser dada a cruzamentos entre genitores que apresentem médias elevadas e divergência ampla nas características de interesse. Contudo, se houver a necessidade de se optar entre genótipos com média de produção intermediária e ampla diversidade ou outros com alta produção e diversidade intermediária, deve prevalecer à última opção.

Rios et al. (2010) relata que grupos formados por apenas um indivíduo apontam na direção de que tais indivíduos sejam mais divergentes em relação aos demais. Isto facilita a projeção dos trabalhos de melhoramento, encontrando os genótipos distintos para futuros cruzamentos.

Conforme Simon (2012) para a obtenção de híbridos em programas de melhoramento genético de plantas é importante na escolha de genitores para extração de linhagens, que sejam complementares para o maior número possível de características de importância agronômica. A seleção de cultivares com base em características individuais é menos vantajosa que aquela baseada em um conjunto de características, principalmente quando o objetivo for produção (LÊDO, 1998).

Quando várias características são avaliadas simultaneamente, as distâncias genéticas relativas podem ser estimadas por procedimentos multivariados, como a distância generalizada de Mahalanobis, as variáveis canônicas, os 
componentes principais, entre outros, sendo que a escolha do método é função da precisão desejada, da facilidade de análise e da forma de obtenção dos dados. Esses estudos podem ser complementados pelos métodos de agrupamento de Tocher e da dispersão em eixos cartesianos, que empregam matrizes de distâncias genéticas, previamente estimadas. A vantagem dos métodos multivariados está no fato de estes permitirem combinar as múltiplas informações contidas na unidade experimental, possibilitando a caracterização dos genótipos com base em um complexo de variáveis (CRUZ et al., 2004).

\section{Características utilizadas na análise multivaridada}

Em análises multivariadas, o emprego de um subconjunto, a partir de um grande número de características, pode não promover mudanças significativas nos resultados. Consequentemente, a avaliação de um menor número de variáveis possibilita a economia de tempo e recursos, tanto na tomada de dados quanto nas análises computacionais, além de reduzir os custos em análises futuras (JOLLIFFE, 1973).

Diversas questões sobre divergência genética têm sido levantadas, como por exemplo, qual seria o critério de escolha das características a serem utilizadas na medida de distância; se realmente todas são necessárias e, se não, quais poderiam ser descartadas; e, ainda, se a distância pode ser ou não afetada com adição ou retirada de variáveis (OLIVEIRA et al., 2004). Esses autores, contudo, relatam que respostas dessas e outras questões não são facilmente obtidas.

Os descritores existentes para a caracterização e avaliação de germoplasma muitas vezes compreendem um número excessivo de variáveis, em razão do completo desconhecimento sobre a importância de cada uma em descrever a variação existente (CRUZ, 1990).

Uma vez que muitas variáveis são redundantes por serem correlacionadas, ou dispensáveis por representarem uma fração desprezível da variação total e diante da necessidade de descrever os materiais conservados em bancos de germoplasmas, metodologias que revelem a importância relativa dos caracteres para a variabilidade, numa avaliação de divergência genética entre populações ou genótipos, são necessárias e representam economia de tempo, mão-de-obra e recursos (COELHO et al., 2007; CRUZ et al., 2004; RODRIGUES et al., 2002).

$\mathrm{Na}$ literatura há estudos que partem de um grande número de descritores, e após análises destes, reduzem em até $50 \%$ seu número (RODRIGUES et al., 2002) de forma a representar melhor a caracterização. Entretanto, deve-se considerar que o conjunto reduzido de caracteres após o descarte precisa se mostrar efetivo na representação da variação total, além de proporcionar vantagens na tomada de dados (TORRES FILHO, 2008).

Para fazer-se uma análise do poder discriminatório dos descritores, torna-se necessário analisar a sua contribuição de forma conjunta através de procedimentos multivariados (COELHO et al., 2010; CRUZ et al., 2004). Dentre os métodos mais utilizados visando determinar a contribuição de cada variável para a divergência genética entre sub amostras estudadas, estão os métodos das variáveis canônicas e o de Singh (1981), que avaliam os indivíduos em vários aspectos (CRUZ et al., 2004).
A presença de divergência genética entre acessos de germoplasma é essencial, porém, os resultados satisfatórios são obtidos somente se o germoplasma utilizado também apresentam valores elevados para as características de interesse (CARVALHO et al, 2003). Conforme Rêgo et al. (2011) os caracteres que contribuírem com um percentual muito baixo ou não contribuírem para a variabilidade detectada podem ser descartadas.

\section{Uso de diversos ambientes/observações}

Há um grande interesse na avaliação da importância relativa dos caracteres visando destacar as características que contribuem pouco para a discriminação dos genótipos avaliados, reduzindo dessa forma, mão de obra, tempo e custos na experimentação (ALVES et al., 2003).

A obtenção de genótipos superiores para diversos caracteres simultaneamente não é um procedimento fácil, geralmente os caracteres agronomicamente mais importantes são governados por vários genes. Além disso, existe a influência do ambiente e das interações genótipos por ambientes, ressaltando-se, também, as relações existentes entre os diversos caracteres de interesse para o melhoramento. Esse conjunto de fatores pode dificultar o processo de seleção (OLIVEIRA, 2008).

Assim, considerando a ocorrência de expressão diferencial dos genes, estudos de diversidade, sempre que possível, deveriam levar em consideração avaliações em ambientes contrastantes para recomendação de genitores potenciais à formação de população base. Diversos estudos têm relatado não só números variáveis de agrupamentos em diferentes ambientes, mas diferentes agrupamentos de genótipos de um ambiente para outro (SÁVIO et al., 2008).

Para obter informações mais consistentes sobre a divergência genética, Bertan et al. (2006) indicam a necessidade da avaliação em mais de um ambiente, sendo tão mais segura quanto maior for o número de ambientes avaliados. Cargnelutti Filho et al. (2008) sugerem que agrupamentos de genótipos com base em apenas uma época de cultivo podem fornecer informações equivocadas, por não considerar o efeito da interação genótipo x ambiente.

A utilização de vários ambientes no estudo da divergência genética é importante, pois reduz a possibilidade de obter informações equivocadas, isto devido que nestes estudos realizados a variabilidade ambiental foi considerada. Estas diferenças entre os ambientes em questão contribuem com a insegurança nos trabalhos que avaliam a divergência genética considerando um único ambiente, desconsiderando a interação genótipo $\mathrm{x}$ ambiente. A este respeito Bertan et al. (2006) afirmam que quanto maior o número de ambientes avaliados, mais seguras são as conclusões. A interação genótipo x ambiente, segundo Dotto et al. (2010) influencia na contribuição das características analisadas para a divergência genética dos genótipos, afetando, deste modo, a consistência das conclusões.

A significância da interação entre genótipos e ambientes pode variar segundo os genótipos, caracteres e fatores ambientais ocorridos nos experimentos. Este fato enfatiza a importância da utilização de vários ambientes no estudo da divergência genética.

Rios et al. (2010) avaliando a divergência genética para o conteúdo de carotenoides em genótipos de milho em dois 
ambientes distintos quanto à fertilidade do solo, observou que o efeito do ambiente na expressão dos caracteres avaliados sugere a necessidade de que esses estudos sejam efetuados em várias condições ambientais e que os resultados mostram a existência de agrupamentos distintos sob diferentes condições de fertilidade do solo, provavelmente, pela expressão diferencial dos genes.

Bainiwal e Jatarsa (1980) relataram que o efeito do ambiente na expressão do caráter coloca dúvidas quanto à segurança das análises da distância de Mahalanobis quando estas são realizadas com dados de um único ambiente, enfatizando a necessidade de que os estudos sejam efetuados em condições ambientais múltiplas. Segundo Falconer (1987), um caráter medido em dois ambientes não deve ser visto como único e sim como dois caracteres.

\section{Resultados na cultura do milho}

Em estudos de divergência genética em milho, a produtividade de grãos foi o atributo que apresentou o maior número de citações na literatura (Tabela 1). Tal resultado era esperado pelo fato de ser o atributo de maior importância econômica na cultura do milho (ROTILI et al., 2012).

Contudo, a contribuição da produtividade na divergência genética foi em média de 14,10\% ( $\pm 3,11)$, com uma amplitude de 0 a 34\% (DOTTO et al., 2010). A produtividade de grãos é um atributo de baixa herdabilidade, pois resulta da atuação do ambiente e de vários genes de pequeno efeito e da interação entre estes fatores (ALLARD, 1971), o que explica está amplitude de resultados encontrados na literatura pesquisada.

A característica que apresentou média de contribuição na divergência genética, com menor erro padrão foi o comprimento da espiga $(2,39 ; \mathrm{n}=8)$. Esse atributo pode interferir, diretamente, no número de grãos por fileira e, por consequente, na produtividade do milho (KAPPES et al., 2009).

A maior contribuição da média, na divergência genética, foi da luteína (37,50\%), foi encontrado por Rios et al. (2010) em dois ambientes distintos. Este caractere pode ser priorizado no estudo de diversidade genética para carotenóides na cultura do milho sem necessidade de quantificação de frações de carotenóides por cromatografia, possibilitando menor custo de análise.

As características $\beta$-criptoxantina; $\beta$-caroteno; $\alpha$-caroteno, Zeaxantina, Pró-VA, apresentaram contribuição da média, na divergência genética de 23,50;7,00;2,50;12,50 e 11,00\%, respectivamente. Os carotenoides presentes nos grãos de milho se dividem em dois grandes grupos: carotenos $(\beta-$ caroteno e a-caroteno e xantofilas (luteína, $\beta$-criptoxantina e zeaxantina), sendo que $90 \%$ desses compostos, nos grãos, são constituídos por luteína e zeaxantina (Goodwin, 1980). A atividade pró-vitamínica A (Pró-VA) é resultante do $\beta$ caroteno e, em menor grau, do a-caroteno e $\beta$-criptoxantina, considerando que os carotenoides a-caroteno e $\beta$ criptoxantina exibem, individualmente, apenas $50 \%$ de atividade pró-vitamínica A (Rodriguez-Amaya \& Kimura, 2004).

As características altura de planta e espiga foram avaliadas por vários autores apresentando contribuição média na divergência genética de 12,67 e 17,33\%, respectivamente (Paixão et al. 2008; Simon et al. 2012; Rotili et al. 2012 ; Dotto et al. 2010).

O diâmetro de espiga foi uma característica que apresentou média de contribuição na divergência genética de $25,60 \%$ considerada alta em relação aos demais atributos, essa característica foi realizada em várias pesquisas, pois é de fácil mensuração. Dotto et al. (2010) com o objetivo de avaliar a divergência genética em cultivares comerciais de milho sob diferentes condições edafoclimáticas no Tocantins, levando em consideração a análise conjunta dos três ambientes constataram que o diâmetro de espiga foi a característica que mais contribuiu para a divergência genética.

A massa 1000 sementes é uma característica que pode ser utilizada para diferentes finalidades, dentre elas a comparação da qualidade de diferentes lotes de sementes, determinação do rendimento de cultivos e mesmo para o cálculo da densidade de semeadura (CUNHA, 2004). A sua contribuição da média na divergência genética, foi de $13,00 \%$.

Pereira et al. (2010) realizaram um estudo visando subsidiar os agricultores alagoanos na escolha de cultivares de milho portadores de atributos agronômicos desejáveis, observaram que o número de dias para atingir o florescimento foi a característica que mais contribuiu para a divergência genética entre os materiais avaliados. Contudo, a contribuição da média, na divergência genética, foi de $32,07 \%$, sendo esta uma característica simples de se observar.

Outra característica importante para a divergência genética é o índice de área foliar que é a relação da área foliar total pela área do solo ocupada por uma planta. Observa-se na Tabela 1 que a sua contribuição da média, na divergência genética, foi de $22,00 \%$.

Sendo assim, observa-se que todas as características, agronômicas ou morfológicas, da cultura do milho (Tabela 1), contribuem para determinação da divergência genética, em maior ou menor proporção.

Tabela 1 - Importância relativa na divergência genética de diversas características, agronômicas ou morfológicas, na cultura $\underline{\text { do milho, encontradas em periódicos }}$

\begin{tabular}{|c|c|c|c|c|c|}
\hline \multirow{2}{*}{ Atributo } & \multirow{2}{*}{$\mathrm{N}^{\mathrm{o}}$ de obs. } & \multicolumn{3}{|c|}{ Contribuição Divergência Genética } & \multirow{2}{*}{$\begin{array}{l}\text { Erro-padrão } \\
\text { da média }\end{array}$} \\
\hline & & Mím & Máx & Média & \\
\hline Produtividade de grãos & 15 & 0 & 34 & 14,10 & 3,11 \\
\hline Altura de espiga & 14 & 0 & 35 & 12,67 & 2,83 \\
\hline Altura de planta & 14 & 2 & 49 & 17,33 & 4,16 \\
\hline Comprimento de espiga & 8 & 6 & 19 & 11,00 & 2,39 \\
\hline Diâmetro de espiga & 7 & 7 & 76 & 25,60 & 10,00 \\
\hline Massa de 1000 ou 100 grãos & 7 & 4 & 21 & 13,00 & 3,24 \\
\hline $\mathrm{N}^{\circ}$ dias para florescimento & 6 & 7 & 57 & 32,07 & 9,36 \\
\hline Produtividade de espiga & 5 & 0 & 29 & 11,20 & 4,90 \\
\hline $\mathrm{N}^{\circ}$ fileiras /espiga & 4 & 11 & 13 & 12,00 & 3,49 \\
\hline
\end{tabular}




\begin{tabular}{|c|c|c|c|c|c|}
\hline $\mathrm{N}^{\circ}$ dias para maturidade & 4 & - & - & - & - \\
\hline Prolificidade & 3 & 0 & 7 & 3,50 & 2,33 \\
\hline $\mathrm{N}^{\circ}$ de grãos/fileira & 3 & 10 & 16 & 13,00 & 4,67 \\
\hline Luteína & 2 & 21 & 54 & 37,50 & 18,03 \\
\hline$\beta$-criptoxantina & 2 & 11 & 36 & 23,50 & 12,50 \\
\hline$\beta$-caroteno & 2 & 1 & 13 & 7,00 & 6,00 \\
\hline$\alpha$-caroteno & 2 & 1 & 4 & 2,50 & 1,50 \\
\hline Zeaxantina & 2 & 9 & 16 & 12,50 & 3,50 \\
\hline Pró-VA & 2 & 9 & 13 & 11,00 & 2,00 \\
\hline Índice de área foliar & 2 & 18 & 26 & 22,00 & 4,00 \\
\hline Comprimento do pendão & 2 & 6 & 8 & 7,00 & 1,00 \\
\hline Carotenoides totais & 2 & 3 & 7 & 5,00 & 2,00 \\
\hline $\mathrm{N}^{\circ}$ de grãos por espiga & 2 & - & - & - & - \\
\hline Demais (mínimo uma obs.) & 19 & 0 & 66 & 10,00 & 3,95 \\
\hline
\end{tabular}
(2010); Oliboni et al. (2010); Paixão et al. (2008); Simon et al. (2012); Nerling et al. (2013); Azad et al. (2012); Zaman et al. (2013).

\section{CONSIDERAÇÕES FINAIS}

Na estimativa da importância relativa, os atributos encontrados com maior frequência nos trabalhos estudados foram: produtividade de grãos, altura de espiga, altura de planta, comprimento de espiga, diâmetro de espiga e massa de grãos, e, os atributos que obtiveram maiores importância relativa na divergência genética em porcentagem, foram: luteína $(37 \%)$, dias para florescimento $(32 \%)$, diâmetro de espiga $(25 \%), \beta$-criptoxantina $(23 \%)$, índice de área foliar (22\%), altura de planta (17\%) e produtividade de grãos $(14 \%)$.

\section{AGRADECIMENTOS}

Ao Conselho Nacional de Desenvolvimento Científico e Tecnológico - CNPq - Brasil, pela concessão da bolsa de doutorado. Ao programa de doutorado da BIONORTE.

\section{REFERÊNCIAS BIBLIOGRÁFICAS}

ALLARD, R. W. Princípios do melhoramento genético de plantas. São Paulo: Edgard Blucher, 381p.

ALVES, R. M.; GARCIA, A. A. F.; CRUZ, E. D.; FIGUEIRA, A. Seleção de descritores botânicoagronômicos para caracterização de germoplasma de cupuaçuzeiro. Pesquisa Agropecuária Brasileira, v. 38, n. 07, jul. 2003, p. 807-818.

AMARAL JÚNIOR, A. T.; THIÉBAUT, J. T. L. Análise multivariada na avaliação da diversidade em recursos genéticos vegetais. Campos dos Goytacazes Universidade Estadual do Norte Fluminense - UENF, CCTA, 1999, 55p.

AZAD, M. A. K.; BISWAS, B. K.; ALAM, N.; ALAM, Sk. S. Genetic diversity in maize (Zea mays L.) inbred lines. The Agriculturists, v. 10, p. 64-70, 2012.

BAINIWAL, C. R.; JATARSA, D. S. Genetic divergence in pigeon pea. Indian Journal of Genetics and Plant Breeding, v. 40, 1980, p. 153-156.
BARAVIERA, C. M. C.; CANEPELLE, C. DOURADO, L. G. A.; AGUERO, N. F. Avaliação de propriedades físicas de grãos de híbridos de milho. Enciclopédia Biosfera, Centro Científico Conhecer, v.10, n.19, p. 291-297, 2014.

BARBIERI, R. L.; LEITE, D. L.; CHOER, E.; SINIGAGLIA, C. Divergência genética entre populações de cebola com base em marcadores morfológicos. Ciência Rural, v. 35, n. 02, mar-abr. 2005, p. 303-308.

BERTAN, I.; CARVALHO, F. F. I.; OLIVEIRA, A. C.; et al. Comparação de métodos de agrupamento na representação da distância morfológica entre genótipos de trigo. Revista Brasileira de Agrociência, v. 12, n. 03, jul-set. 2006, p. 301-308.

CARGNELUTTI FILHO, A.; RIBEIRO, N. D.; REIS, R. C. P. dos.; et al. Comparação de métodos de agrupamento para o estudo da divergência genética em cultivares de feijão. Ciência Rural, v. 38 , n. 08 , nov. 2008 , p. 2138 2145.

CARVALHO, L. P. de.; LANZA, M. A.; FALLIERI, J.; et al. Análise da diversidade genética entre acessos de banco ativo de germoplasma de algodão. Pesquisa Agropecuária Brasileira, v. 38, n. 10, out. 2003, p.1149-1155.

COELHO, C. M. M.; COIMBRA, J. L. M.; SOUZA, C. A.; BOGO, A.; GUIDOLIN, A. F. Diversidade genética em acessos de feijão (Phaseolus vulgaris L.). Ciência Rural, v. 37, n. 05, set-out. 2007. p. 1241-1247.

COELHO, C. M. M.; ZILIO, M.; SOUZA, C. A.; GUIDOLIN, A. F.; et al. Características morfoagronômicas de cultivares crioulas de feijão comum em dois anos de cultivo. Semina: Ciências Agrárias, v. 31, (Suplemento 1). 2010. p. 1177-1186.

CRUZ, C. D. Aplicação de algumas técnicas multivariadas no melhoramento de plantas. 1990. 188p. Tese (Doutorado) Universidade de São Paulo, Piracicaba, 1990.

CRUZ, C. D.; FERREIRA F. M.; PESSONI, L. A. Biometria Aplicada ao Estudo da Diversidade Genética. Visconde do Rio Branco-MG: Suprema, 2011. 620p. 
CRUZ, C. D.; REGAZZI, A. J.; CARNEIRO, P. C. S. Modelos biométricos aplicados ao melhoramento genético. 3. ed. Viçosa: UFV, 2004. 480p.

CUI, Z.; CARTER J. R. T. E.; BURTON, J. W.; et al. Phenotypic diversity of modern Chinese and North American soybean cultivars. Crop Science, v. 41, p. 19541967, 2001.

CUNHA, M. B. da Comparação de métodos para a obtenção do peso de mil sementes de aveia preta e soja. UFPEL, 2004.

DOTTO, A. P.; LANA, M. C.; STEINER, F.; et al. Produtividade do milho em resposta à inoculação com Herbaspirillum seropedicae sob diferentes níveis de nitrogênio. Revista Brasileira de Ciências Agrárias, v. 5, n. 03, jul.-set. 2010. p. 376-382.

FALCONER, D. S. Introdução à genética quantitativa. Vicosa, MG: UFV, 1987. 279 p.

GONÇALVES, D. L.; AMBROZIO, V. C.; BARELLI, M. A. A.; et al. Divergência genética de acessos tradicionais de feijoeiros através de características da semente. Bioscience Journal, v. 30, n. 6, nov-dez. 2014. p. 16711681 .

HALLAUER, A. R.; MIRANDA FILHO, J. B. de Quantitative genetics in maize breeding. $2^{\circ}$ ed. Ames: Iowa State University Press, 1995. 468p.

JOLLIFFE, I. T. Discarding variables in a principal component analysis; II Real data. Applied Statistics, v. 22, n. 01,1973 . p. 21-31.

KAPPES, C.; CARVALHO, M. A. C.; YAMASHITA, O. M.; et al. Influência do nitrogênio no desempenho produtivo do milho cultivado na segunda safra em sucessão à soja. Pesquisa Agropecuária Tropical, v. 39, n. 03, p. 251-259, 2009.

KUREK, A. J.; CARVALHO, F. I. F.; ASSMANN, I. C.; et al. Capacidade combinatória como critério de eficiência na seleção de genitores em feijoeiro. Pesquisa Agropecuária Brasileira, v. 36, n. 04, abr. 2001. p. 645651

LÊDO, F. J. S. Diversidade genética e análise dialélica da eficiência nutricional para nitrogênio em alface (Lactuca sativa L.). 1998. 87 p. Tese (Doutorado) - Universidade Federal de Viçosa, Viçosa, 1998.

MELO, W. M. C.; VON PINHO, R. G.; FERREIRA, D. F. Capacidade combinatória e divergência genética em híbridos comerciais de milho. Ciência e Agrotecnologia, v. 25, n. 04, jul.-ago. 2001. p. 821-830.

MISSIO, R. F.; MORAES, M. L. T.; DIAS, L. A. S. Efeito do desbaste seletivo sobre a divergência genética em progênies de Pinus caribaea Morelet var. bahamensis. Scientia Forestalis, n. 73, 2007. p. 27-36.
NERLING, D.; COELHO, C.; MEDEIROS, M.; NODARI, R. O. Genetic diversity for physiological quality of seeds from corn (Zea mays L.) intervarietal crossbreeds. Journal of Seed Science, v. 35, n. 4, 2013, p. 449-456.

OLIBONI, R.; FARIA, M. V.; NEUMANN, M.; et al. Genetic divergence among maize hybrids and correlations with heterosis and combining ability. Acta Scientiarum Agronomy, v. 34, n.1, jan-mar. 2012. p. 37-44.

OLIVEIRA, A. C. B.; SEDIYAMA, M. A. N.; PEDROSA, M. W.; et al. Divergência genética e descarte de variáveis em alface cultivada sob sistema hidropônico. Acta Scientiarum, v.26, n. 02, 2004. p. 211-217.

OLIVEIRA, G. V. Potencial genético de famílias de feijoeiro da população Ouro Negro x BRS Valente. 2008. 139 p. Tese (Doutorado) - Universidade Federal de Viçosa, UFV, Viçosa - MG, 2008.

PAIXÃO, S. L.; CAVALCANTE, M.; A P. V.; MADALENA J. A. S.; PEREIRA R. G. Divergência genética e avaliação de populações de milho em diferentes ambientes no estado de Alagoas. Revista Caatinga, v. 21, p. 191-195, 2008.

PEREIRA, R. G.; ALBUQUERQUE, A. W.; NUNES, SOUSA, et al. Comportamento de cultivares de milho nos tabuleiros costeiros do estado de Alagoas. Revista Verde de Agroecologia e Desenvolvimento Sustentável, v. 5, n. 2, abr-jun. 2010. p. 54-63.

REDDY, S. M.; KUMAR, S. S.; SUDHARSHAN, M. R.; et al. Genetic Divergence In Baby Corn (Zea Mays L.). International Journal of Innovative Research \& Development, v. 2, n. 8, ago. 2013. p. 300-304.

RÊGO, E. R.; REGO, M. M.; CRUZ, C. D; FINGER, F. L; et al. Phenotypic diversity, correlation and importance of variables for fruit quality and yield traits in Brazilian peppers (Capsicum baccatum). Genetic Resources and Crop Evolution, v. 58, n. 6, nov. 2011. p. 909-918.

RIOS S. A.; BORÉM A.; GUIMARÃES P. E. O.; et al. Divergência genética entre genótipos de milho quanto ao teor de carotenoides nos grãos. Revista Brasileira de Milho e Sorgo, v.9, p. 277-286, 2010.

RODRIGUES, L. S.; ANTUNES, I. F.; TEIXEIRA, M. G.; et al. Divergência genética entre cultivares locais e cultivares melhoradas de feijão. Pesquisa Agropecuária Brasileira, v. 37, n. 9 , set. 2002. p. 1275-1284.

ROTILI, E. A.; CANCELLIER, L. L.; DOTTO, M. A.; et al. Divergência genética em genótipos de milho, no estado do Tocantins. Ciência Agronômica, v. 43, n. 03, jul-set. 2012. p. 516-521.

SÁVIO, F. L.; FARIA, P. N.; PEREIRA, W. A.; et al. Divergência genética em híbridos de sorgo cultivados sob diferentes níveis de fósforo, em solução nutritiva. Revista Brasileira de Milho e Sorgo, v.7, n. 03. 2008. p. 305-321. 
SIMON, G. A.; KAMADA, T.; MOITEIRO, M. Divergência genética em milho de primeira e segunda safra. Semina: Ciências Agrárias, v. 33, n. 02, abr. 2012. p. 449-458.

SINGH, D. The relative importance of characters affecting genetic divergence. Indian Journal of Genetics and Plant Breeding, v. 41, n. 02, p. 237-245, 1981.

TORRES FILHO, J. Caracterização morfo-agronômica, seleção de descritores e associação entre a divergência genética e a heterose no meloeiro. 2008. 150p. Tese (Doutorado) - Universidade Federal Rural do Semi-Árido, Mossoró, 2008.

ZAMAN. M. A.; ALAM. M. A. Genetic diversity in exotic maize (Zea mays L.) hybrids. Bangladesh J. Agril. Res. v.38, p. 335-341, 2013 